\title{
Kynurenines in chronic neurodegenerative disorders: future therapeutic strategies
}

D. Zádori ${ }^{1}$, P. Klivényi ${ }^{1}$, E. Vámos ${ }^{1}$, F. Fülöp ${ }^{2}$, J. Toldi $^{3}$ and L. Vécsei ${ }^{1 *}$

${ }^{1}$ Department of Neurology, Albert Szent-Györgyi Clinical Centre, University of Szeged, Semmelweis u. 6, H-6725 Szeged, Hungary

${ }^{2}$ Department of Pharmaceutical Chemistry, University of Szeged, Eötvös u. 6, H-6720 Szeged, Hungary

${ }^{3}$ Department of Physiology, Anatomy and Neuroscience, University of Szeged, Közép fasor 52, H-6726 Szeged, Hungary

"Author for correspondence: László Vécsei, MD, PhD, DSc, Department of Neurology, Albert Szent-Györgyi Clinical Centre, University of Szeged, Semmelweis u. 6., H-6725 Szeged,

Hungary; Phone: +36 62 545348; Fax: +36 62 545597; E-mail: vecsei@nepsy.szote.u-szeged.hu

Run-in Heading: Kynurenines and neurodegeneration 


\begin{abstract}
Parkinson's, Alzheimer's and Huntington's diseases are chronic neurodegenerative disorders of a progressive nature which lead to a considerable deterioration of the quality of life. Their pathomechanisms display some common features, including an imbalance of the tryptophan metabolism. Alterations in the concentrations of neuroactive kynurenines can be accompanied by devastating excitotoxic injuries and metabolic disturbances. From therapeutic considerations, possibilities that come into account include increasing the neuroprotective effect of kynurenic acid, or decreasing the levels of neurotoxic 3-hydroxy-L-kynurenine and quinolinic acid. The experimental data indicate that neuroprotection can be achieved by both alternatives, suggesting opportunities for further drug development in this field.
\end{abstract}

Keywords: kynurenines, kynurenic acid, kynurenine aminotransferase, Parkinson's disease, Alzheimer's disease, Huntington's disease 


\section{Introduction}

Despite the different clinical and neuropathological entities, the pathomechanisms of chronic neurodegenerative disorders reveal a number of common features in their devastating processes. A disturbance of the mitochondrial function, glutamate excitotoxicity and a change in the tryptophan metabolism all surely accompany the development of Parkinson's disease (PD), Alzheimer's disease (AD) and Huntington's disease (HD), among others (Fig. 1).

\section{Glutamate excitotoxicity and the kynurenine pathway}

The enhanced release of glutamate, the main excitatory amino acid in the brain, gives rise to prolonged stimulation of its receptors and, via a complex pathomechanism, induces devastation of the postsynaptic neurons. This process of glutamate-induced excitotoxicity, first described nearly four decades ago (Olney, 1969), may be linked with a mitochondrial dysfunction, because the energy impairment can lead to partial membrane depolarization, resulting in relief of the magnesium block of the N-methyl-D-aspartate (NMDA) channel. Thus, even in physiological concentrations, glutamate can evoke downstream events such as a $\mathrm{Ca}^{2+}$ overload and free radical generation, inducing a self-propagating process (Henneberry 1997).

The kynurenine pathway is the main pathway of the tryptophan metabolism (Wolf 1974), which is primarily responsible for $\mathrm{NAD}^{+}$and $\mathrm{NADP}^{+}$production (Fig. 2). The central compound of the pathway is L-kynurenine (L-KYN), which can be metabolized in two distinct routes to kynurenic acid (KYNA) or to 3-hydroxy-Lkynurenine (3-OH-L-KYN) and quinolinic acid (QUIN; Guidetti et al. 1995). These three metabolites are commonly referred to as neuroactive kynurenines (reviewed by Vécsei 2005; Sas et al. 2007; Robotka et al. 2008). KYNA is formed from L-KYN by an irreversible transamination catalyzed by three subtypes of kynurenine aminotransferases (KATs; Okuno et al. 1991; Yu et al. 2006) and mitochondrial aspartate aminotransferase (mitAAT). KAT-II has been demonstrated to be the main KYNA-producing enzyme in the rat and human brains, while in the mouse brain mitAAT possesses the highest activity and KATII the lowest (Guidetti et al. 2007). KYNA is a broad-spectrum endogenous antagonist of ionotropic excitatory amino acid receptors (Perkins and Stone 1982). 
In micromolar concentrations, it acts as a competitive antagonist at the strychnineinsensitive glycine-binding site of the NMDA receptor (Kessler et al. 1989) and exerts weak antagonistic effects on the $\alpha$-amino-3-hydroxy-5-methyl-4-isoxazole propionic acid (AMPA) and kainate receptors (Birch et al. 1988). It has been reported that KYNA in low (nanomolar to micromolar) concentrations can facilitate AMPA receptor responses (Prescott et al. 2006), but the concentration range is controversial: KYNA in micromolar concentrations was recently claimed to have a neuroinhibitory effect, whereas in nanomolar concentrations it behaves as a facilitator (Rózsa et al. 2008). It is also important that KYNA noncompetitively blocks the $\alpha 7$-nicotinic acetylcholine receptors (Hilmas et al. 2001), activation of which at the presynaptic site is involved in the regulation of glutamate release (Marchi et al. 2002). Another interesting fact is that the neuronal expression of KAT-I seems to have effects on developmental processes, such as programmed cell death (Csillik et al. 2002b). QUIN and 3-OH-L-KYN, both neurotoxic compounds, are formed by the action of 3-hydroxyanthranilate 3,4-dioxygenase and kynurenine 3-hydroxylase, respectively (Foster et al. 1986; Battie and Verity 1981). QUIN is a weak, but specific competitive agonist of the NMDA receptor subgroup containing the NR2A and NR2B subunits (de Carvalho et al. 1996), with low receptor affinity. Via the direct activation of NMDA receptors (Stone and Perkins 1981) or the release and uptake inhibition of endogenous glutamate (Connick and Stone 1988; Tavares et al. 2002), it can cause excitotoxicity. It also induces lipid peroxidation (Rios and Santamaria 1991) and the production of reactive oxygen species (Behan et al. 1999). The effects of 3$\mathrm{OH}-\mathrm{L}-\mathrm{KYN}$ are mediated by free radicals and not glutamate receptors (Eastman and Guilarte 1990; Okuda et al. 1998). Some of its deleterious actions could be due to its metabolite, 3-hydroxyanthranilic acid (3-OH-ANA), which readily undergoes auto-oxidation with the production of $\mathrm{O}_{2}{ }^{--}$(Dykens et al. 1987), and it has also been shown to be neurotoxic (Jhamandas et al. 1990). 


\section{The role of kynurenine pathway abnormalities in chronic neurodegenerative disorders}

\section{Parkinson's disease}

PD is a progressive neurodegenerative disorder, clinically characterized by resting tremor, rigidity, bradykinesia and postural instability. The pathological hallmarks are a preferential loss of dopaminergic neurons in the substantia nigra pars compacta (SNPC) and the presence of Lewy bodies. Neurons in the substantia nigra possess NMDA receptors and receive glutamatergic input from the subthalamic nucleus, cerebral cortex, amygdala and pedunculopontine and laterodorsal tegmental nuclei (reviewed by Misgeld 2004). In consequence of the defect in mitochondrial complex I activity (Reichmann and Riederer 1989; Schapira et al. 1989), the dopaminergic neurons become more vulnerable to excitotoxicity (reviewed by Beal 1998). This process may be linked with a disturbance of the tryptophan metabolism, as suggested by the observation that the expression of KAT-I in the substantia nigra of mice is decreased after 1-methyl-4phenyl-1,2,3,6,-tetrahydropyridine (MPTP; for the inhibition of mitochondrial complex I) treatment (Knyihár-Csillik et al. 2004). Further, densitometric analysis has proved that 6-hydroxydopamine (a free radical generator in catecholaminergic neurons) treatment considerably diminishes not only tyrosine hydroxylase, but also KAT-I immunoreactivity in the remaining SNPC neurons (Knyihár-Csillik et al. 2006). In rat cerebral cortical slices, 1-methyl-4-phenylpyridinium ion ( $\mathrm{MPP}^{+}$; the neuroactive metabolite of MPTP) considerably diminished KAT-II activity, with the resulting depletion of KYNA (Luchowski et al. 2002). In accordance with these findings, lowered KYNA concentrations have been measured in the frontal cortex, putamen and SNPC of patients with PD (Ogawa et al. 1992), and thus KYNA is probably unable to inhibit NMDA receptors effectively and to prevent excitotoxicity. Conversely, 3-OH-L-KYN concentrations have been found to be elevated, probably contributing to the oxidative damage seen in PD.

\section{Alzheimer's disease}

$\mathrm{AD}$ is likewise a progressive neurodegenerative disorder accompanied by dementia and characterized by neuropathological lesions such as neurofibrillary tangles and $\beta$-amyloid $(\mathrm{A} \beta)$ plaques, mainly in the areas responsible for memory 
formation consisting of glutamatergic circuits. A marked decrease in mitochondrial complex IV activity suggests that an energy impairment plays a crucial role in the development of AD, too (Kish et al. 1992). Together with other enzyme disturbances, it can result in ATP depletion and the increased production of free radicals and $A \beta$. Glutamate excitotoxicity is a further key event in the pathogenesis of $\mathrm{AD}$, for a $\mathrm{Ca}^{2+}$ overload can lead to the increased activation of kinases with the consequential formation of neurofibrillary tangles due to tau hyperphosphorylation (reviewed by Greenamyre and Young 1989). Alterations in the kynurenine pathway have also been implicated in the pathological process. Sodium azide (inhibitor of mitochondrial complex IV) treatment can alter the expression of KAT-I: the glial immunoreactivity has been found to be decreased, while the neurons have started to express KAT-I (Knyihár-Csillik et al. 1999). A slightly elevated hippocampal KYNA concentration has been found in postmortem AD brains (Baran et al. 1999), with no alterations in the activities of either KAT-I or KAT-II in this key brain region in AD. However, the same study revealed a significantly elevated KYNA concentration with an increased KAT-I activity in the caudate nucleus and putamen, and a moderately enhanced KAT-II activity only in the putamen. This may be a compensatory mechanism due to the pronounced degeneration of the corticostriatal pathway in AD (Francis et al. 1993), with increased glutamate binding in the striatum (Ułas et al. 1994). The 3$\mathrm{OH}-\mathrm{L}-\mathrm{KYN}$ content in the AD brain merely tends to decrease and does not seem to have an important role in the pathomechanism. However, $\mathrm{A} \beta$ can induce the production of QUIN by the microglia and macrophages to a neurotoxic level (reviewed by Guillemin and Brew 2002). This was proved by the immunohistochemical analysis of post-mortem AD brains, where massive increases were found both in indoleamine 2,3-dioxygenase (the enzyme responsible for the production of L-KYN) and in QUIN immunoreactivity, mainly in the perimeter of senile plaques (Guillemin et al. 2005). These data suggest the upregulation of the kynurenine pathway in $\mathrm{AD}$, leading mainly to the excessive local production of QUIN due to neuroinflammatory processes, and also to an elevation in KYNA level, which is nevertheless unable to alleviate the deleterious neurotoxic effects of QUIN. 


\section{Huntington's disease}

HD is an autosomal dominantly inherited neurodegenerative disorder, characterized clinically by cognitive, psychiatric and motor symptoms and pathologically by the development of neuronal intranuclear inclusions in certain brain regions. The loss of medium-sized spiny neurons (MSNs) in the striatum is most pronounced. A mitochondrial dysfunction is indicated by a decreased activity of succinate dehydrogenase in post-mortem HD brains (Stahl and Swanson 1974). 3-Nitropropionic acid (inhibitor of succinate dehydrogenase) treatment reduces the activity of KAT-I most markedly in the striatum of the rat brain, suggesting a link between the metabolic disturbances and an altered tryptophan metabolism in HD (Csillik et al. 2002a). Further, when rat cerebral cortical slices were used, the activities of KAT-I and KAT-II proved to be decreased, with the resulting depletion of KYNA (Luchowski et al. 2002). Glutamate excitotoxicity too may play an important role in the development of HD (Coyle and Schwarcz 1976; McGeer and McGeer 1976; DiFiglia 1990). Selective impairment of the MSNs may be explained by their receiving massive glutamatergic inputs from the cortex and the thalamus (Fonnum et al. 1981; Smith et al. 2004). On the other hand, the NMDA receptors are present in especially high amounts on the spines of the MSNs, and the pattern of expression of the receptor subunits differs from that of the other striatal neurons (Landwehrmeyer et al. 1995). An imbalance has been demonstrated between the levels of the neuroactive kynurenines in the striatum in different stages of HD (Guidetti et al. 2004): the level of QUIN is significantly elevated in low-grade HD brains, but normal or decreased in higher-grade cases. The elevation in QUIN concentration correlates well with the increased activity of its producing enzyme, 3hydroxyanthranilate 3,4-dioxygenase in HD brains (Schwarcz et al. 1988). The pathogenetic role of QUIN in the development of HD is supported by the fact that its intrastriatal injection is highly applicable for the animal modelling of HD (Schwarcz and Köhler 1983; Beal et al. 1986; Vécsei and Beal 1991). A KYNA level deficiency and decreased activities of KAT-I and KAT-II in the striatum of HD patients (Beal et al. 1990; Jauch et al. 1995) have also been proposed to be related to the development of the disease. In correlation to the findings detailed above, young mice with decreased KYNA and normal 3-OH-L-KYN and QUIN concentrations due to the targeted deletion of KAT-II displayed an increased 
vulnerability to the intrastriatal injection of QUIN as compared with the wild-type controls (Sapko et al. 2006). The striatal concentration of 3-OH-L-KYN, which potentiates the neurotoxic effects of QUIN in the rat striatum (Guidetti and Schwarcz 1999), changes in parallel with the QUIN level in HD; Person and Reynolds (1992) have reported it to be elevated. The roles of neuroactive kynurenines accompanying the development of HD have been investigated by means of a yeast genomic screen, too, which revealed that the deletion of the KYNA-producing enzyme enhances mutant huntingtin-mediated toxicity, whereas mainly the deletion of 3-OH-L-KYN, but also that of the QUIN-producing enzyme ameliorates it (Giorgini et al. 2005).

\section{Modulation of the kynurenine pathway as a future therapeutic strategy}

From a therapeutic aspect, the findings detailed above suggest several possibilities which might be utilized in an effort to prevent or at least to mitigate these neurodegenerative processes. As concerns the kynurenines, enhancement of the effects of KYNA or reduction of the levels of 3-OH-L-KYN and QUIN may come into consideration (reviewed by Schwarcz 2004). As the blood-brain penetration of KYNA is poor (Fukui et al. 1991), the former aim may be achieved by the administration of KYNA analogues (reviewed by Stone 2000) or pro-drugs that can cross the blood-brain barrier or by inducing an elevation of the endogenous KYNA level. In relation to PD, the co-infusion of exogenous KYNA with either QUIN or NMDA into the SNPC led to the preservation of striatal tyrosine hydroxylase activity (Miranda et al. 1997). In accordance with these results, KYNA, but surprisingly not the more selective glycine/NMDA receptor antagonist 7-chlorokynurenic acid (7-Cl-KYNA), afforded partial protection against the intrastriatal neurotoxic effect of $\mathrm{MPP}^{+}$in rats (Merino et al. 1999). Accordingly, 5,7-dichlorokynurenic acid too did not reverse the AD-type abnormal hyperphosphorylation of tau induced by the phosphatase inhibitor okadaic acid in hippocampal organotypic cultures ( $\mathrm{Li}$ et al. 2004). However, the systemic administration of 4-chlorokynurenine (4-Cl-KYN), the blood-brain penetrable pro-drug of 7-Cl-KYNA, did prevent quinolinate-induced neurotoxicity in the rat hippocampus (Wu et al. 2000). Furthermore, it also provided protection in the rat striatum in the quinolinate and malonate (inhibitor 
of succinate dehydrogenase) models of HD (Guidetti et al. 2000). The seeming controversy between these experimental findings can be explained on the one hand by the fact that the halogenation of KYNA results in compounds that are highly selective for the glycine site of NMDA receptors (Leeson et al. 1991) and can mainly prevent NMDA receptor-mediated excitotoxicity, but neurodegenerative processes involve a wider spectra of neurotransmitter receptors and intracellular signalling pathways. On the other hand, 4-Cl-KYN can be metabolized to 4-chloro-3-hydroxyanthranilate, a powerful inhibitor of QUIN synthesis (Parli et al. 1980), broadening the modes of neuroprotective action. However, it is important to mention here that the inhibition of kynurenine 3hydroxylase rather selected, as blockade of 3-hydroxyanthranilate 3,4dioxygenase activity may result in the accumulation of 3-OH-ANA (FornstedtWallin et al. 1999), which can exert neurotoxic effects, thereby decreasing the potency of neuroprotection. The combination of nicotinylalanine, an agent that inhibits both kynurenine 3-hydroxylase and kynureninase activity, with L-KYN and probenecid, an inhibitor of organic acid transport, protects the dopaminergic cells in the SNPC against NMDA and QUIN-induced excitotoxicity through the elevated KYNA level (Miranda et al. 1997), and also alleviates QUIN-mediated neurotoxicity in the rat striatum (Harris et al. 1998). Furthermore, 3,4-dimethoxyN-[4-(3-nitrophenyl)thiazol-2-yl]benzenesulfonamide (Ro 61-8048), a potent noncompetitive inhibitor of kynurenine 3-hydroxylase, proved to be protective in a yeast model of HD (Giorgini et al. 2005). Although these small molecule kynurenine 3-hydroxylase inhibitors alone cannot elevate the physiological level of KYNA (Moroni et al. 1991), Amori et al. (2009) made the interesting recent finding that in excitotoxically lesioned neuron-depleted striata $(1 S, 2 S)-2-(3,4-$ dichlorobenzoyl)-cyclopropane-1-carboxylic acid (UPF 648) moderately enhanced the KYNA synthesis.

\section{Conclusion}

The encouraging experimental data emerging from the activities in the field of neuroscience, dealing with the connection between chronic neurodegenerative disorders and the kynurenine pathway, justify the continuation of research in this area, with a view to future drug development. The uses of 4-Cl-KYN and small molecule enzyme inhibitors alike have a great promise, and the design of blood- 
brain penetrable KYNA analogues with preserved pharmacological activity also would be a successful therapeutic strategy.

\section{Acknowledgement}

This work was supported by grants RET-NORT 08/2004 and ETT 215/2006.

\section{References}

Amori L, Guidetti P, Pellicciari R, Kajii Y, Schwarcz R (2009) On the relationship between the two branches of the kynurenine pathway in the rat brain in vivo. J Neurochem 109:316-325

Baran H, Jellinger K, Deecke L (1999) Kynurenine metabolism in Alzheimer's disease. J Neural Transm 106:165-181

Battie C, Verity MA (1981) Presence of kynurenine hydrolase in developing rat brain. J Neurochem 36:1308-1310

Beal MF (1998) Excitotoxicity and nitric oxide in Parkinson's disease pathogenesis. Ann Neurol 44:S110-114

Beal MF, Kowall NW, Ellison DW, Mazurek MF, Swartz KJ, Martin JB (1986) Replication of the neurochemical characteristics of Huntington's disease by quinolinic acid. Nature 321:168-171

Beal MF, Matson WR, Swartz KJ, Gamache PH, Bird ED (1990) Kynurenine pathway measurements in Huntington's disease striatum: evidence for reduced formation of kynurenic acid. J Neurochem 55:1327-1339

Behan WM, McDonald M, Darlington LG, Stone TW (1999) Oxidative stress as a mechanism for quinolinic acid-induced hippocampal damage: protection by melatonin and deprenyl. $\mathrm{Br} \mathrm{J}$

Pharmacol 128:1754-1760

Birch PJ, Grossman CJ, Hayes AG (1988) Kynurenate and FG9041 have both competitive and non-competitve antagonist actions at excitatory amino acid receptors. Eur J Pharmacol 151:313315

Connick JH, Stone TW (1988) Quinolinic acid effects on amino acid release from the rat cerebral cortex in vitro and in vivo. Br J Pharmacol 93:868-876

Coyle JT, Schwarcz R (1976) Lesion of striatal neurons with kainic acid provides a model for Huntington's chorea. Nature 263:244-246

Csillik A, Knyihár E, Okuno E, Krisztin-Péva B, Csillik B, Vécsei L (2002a) Effect of 3nitropropionic acid on kynurenine aminotransferase in the rat brain. Exp Neurol 177:233-241

Csillik AE, Okuno E, Csillik B, Knyihár E, Vécsei L (2002b) Expression of kynurenine aminotransferase in the subplate of the rat and its possible role in the regulation of programmed cell death. Cereb Cortex 12:1193-1201

de Carvalho LP, Bochet P, Rossier J (1996) The endogenous agonist quinolinic acid and the non endogenous homoquinolinic acid discriminate between NMDAR2 receptor subunits. Neurochem Int 28:445-452 
DiFiglia M (1990) Excitotoxic injury of the neostriatum: a model for Huntington's disease. Trends Neurosci 13:286-289

Dykens JA, Sullivan SG, Stern A (1987) Oxidative reactivity of the tryptophan metabolites 3hydroxyanthranilate, cinnabarinate, quinolinate and picolinate. Biochem Pharmacol 36:211-217 Eastman CL, Guilarte TR (1990) The role of hydrogen peroxide in the in vitro cytotoxicity of 3hydroxykynurenine. Neurochem Res 15:1101-1107

Fonnum F, Storm-Mathisen J, Divac I (1981) Biochemical evidence for glutamate as neurotransmitter in corticostriatal and corticothalamic fibres in rat brain. Neuroscience 6:863-873 Fornstedt-Wallin B, Lundström J, Fredriksson G, Schwarcz R, Luthman J (1999) 3Hydroxyanthranilic acid accumulation following administration of the 3-hydroxyanthranilic acid 3,4-dioxygenase inhibitor NCR-631. Eur J Pharmacol 386:15-24

Foster AC, White RJ, Schwarcz R (1986) Synthesis of quinolinic acid by 3-hydroxyanthranilic acid oxygenase in rat brain tissue in vitro. J Neurochem 47:23-30

Francis PT, Sims NR, Procter AW, Bowen DM (1993) Cortical pyramidal neurone loss may cause glutamatergic hypoactivity and cognitive impairment in Alzheimer's disease: investigative and therapeutic perspectives. J Neurochem 60:1589-1604

Fukui S, Schwarcz R, Rapoport SI, Takada Y, Smith OR (1991) Blood-brain barrier transport of kynurenines: implications for brain synthesis and metabolism. J Neurochem 56:2007-2017 Greenamyre JT, Young AB (1989) Excitatory amino acids and Alzheimer's disease. Neurobiol Aging 10:593-602

Giorgini F, Guidetti P, Nguyen Q, Bennett SC, Muchowski PJ (2005) A genomic screen in yeast implicates kynurenine 3-monooxygenase as a therapeutic target for Huntington disease. Nat Genet 37:526-531

Guidetti P, Amori L, Sapko MT, Okuno E, Schwarcz R (2007) Mitochondrial aspartate aminotransferase: a third kynurenate-producing enzyme in the mammalian brain. J Neurochem 102:103-111

Guidetti P, Eastman CL, Schwarcz R (1995) Metabolism of [5-3H]kynurenine in the rat brain in vivo: evidence for the existence of a functional kynurenine pathway. J Neurochem 65:2621-2632 Guidetti P, Luthi-Carter RE, Augood SJ, Schwarcz R (2004) Neostriatal and cortical quinolinate levels are increased in early grade Huntington's disease. Neurobiol Dis 17:455-461 Guidetti P, Schwarcz R (1999) 3-Hydroxykynurenine potentiates quinolinate, but not NMDA toxicity in the rat striatum. Eur J Neurosci 11:3857-3863

Guidetti P, Wu HQ, Schwarcz R (2000) In situ produced 7-chlorokynurenate provides protection against quinolinate- and malonate-induced neurotoxicity in the rat striatum. Exp Neurol 163:123130

Guillemin GJ, Brew BJ (2002) Implications of the kynurenine pathway and quinolinic acid in Alzheimer's disease. Redox Rep 7:199-206

Guillemin GJ, Brew BJ, Noonan CE, Takikawa O, Cullen KM (2005) Indolamine 2,3 dioxygenase and quinolinic acid immunoreactivity in Alzheimer's disease hippocampus. Neuropathol Appl Neurobiol 31:395-404 
Harris CA, Miranda AF, Tanguay JJ, Boegman RJ, Beninger RJ, Jhamandas K (1998) Modulation of striatal quinolinate neurotoxicity by elevation of endogenous brain kynurenic acid. $\mathrm{Br} \mathrm{J}$

Pharmacol 124:391-399

Henneberry RC (1997) Excitotoxicity as a consequence of impairment of energy metabolism: the energy-linked excitotoxic hypothesis. In: Beal MF, Howell N, Bodis-Wollner I (eds) Mitochondria $\&$ free radicals in neurodegenerative diseases. Wiley, New York, pp 111-143

Hilmas C, Pereira EF, Alkondon M, Rassoulpour A, Schwarcz R, Albuquerque EX (2001) The brain metabolite kynurenic acid inhibits alpha7 nicotinic receptor activity and increases nonalpha7 nicotinic receptor expression: physiopathological implications. J Neurosci 21:7463-7473 Jauch D, Urbańska EM, Guidetti P, Bird ED, Vonsattel JP, Whetsell WO Jr, Schwarcz R (1995) Dysfunction of brain kynurenic acid metabolism in Huntington's disease: focus on kynurenine aminotransferases. J Neurol Sci 130:39-47

Jhamandas K, Boegman RJ, Beninger RJ, Bialik M (1990) Quinolinate-induced cortical cholinergic damage: modulation by tryptophan metabolites. Brain Res 529:185-191

Kessler M, Terramani T, Lynch G, Baudry M (1989) A glycine site associated with N-methyl-Daspartic acid receptors: characterization and identification of a new class of antagonists. $\mathrm{J}$ Neurochem 52:1319-1328

Kish SJ, Bergeron C, Rajput A, Dozic S, Mastrogiacomo F, Chang LJ, Wilson JM, DiStefano LM, Nobrega JN (1992) Brain cytochrome oxidase in Alzheimer's disease. J Neurochem 59:776-779 Knyihár-Csillik E, Chadaide Z, Mihály A, Krisztin-Péva B, Fenyő R, Vécsei L (2006) Effect of 6hydroxydopamine treatment on kynurenine aminotransferase-I (KAT-I) immunoreactivity of neurons and glial cells in the rat substantia nigra. Acta Neuropathol 112:127-137

Knyihár-Csillik E, Csillik B, Pákáski M, Krisztin-Péva B, Dobó E, Okuno E, Vécsei L (2004) Decreased expression of kynurenine aminotransferase-I (KAT-I) in the substantia nigra of mice after 1-methyl-4-phenyl-1,2,3,6-tetrahydropyridine (MPTP) treatment. Neuroscience 126:899-914 Knyihár-Csillik E, Okuno E, Vécsei L (1999) Effects of in vivo sodium azide administration on the immunohistochemical localization of kynurenine aminotransferase in the rat brain.

Neuroscience 94:269-277

Landwehrmeyer GB, Standaert DG, Testa CM, Penney JB Jr, Young AB (1995) NMDA receptor subunit mRNA expression by projection neurons and interneurons in rat striatum. J Neurosci 15:5297-5307

Leeson PD, Baker R, Carling RW, Curtis NR, Moore KW, Williams BJ, Foster AC, Donald AE, Kemp JA, Marshall GR (1991) Kynurenic acid derivatives - structure-activity relationships for excitatory amino acid antagonism and identification of potent and selective antagonists at the glycine site on the NMDA receptor. J Med Chem 34:1243-1252

Li L, Sengupta A, Haque N, Grundke-Iqbal I, Iqbal K (2004) Memantine inhibits and reverses the Alzheimer type abnormal hyperphosphorylation of tau and associated neurodegeneration. FEBS Lett 566:261-269

Luchowski P, Luchowska E, Turski WA, Urbanska EM (2002) 1-Methyl-4-phenylpyridinium and 3-nitropropionic acid diminish cortical synthesis of kynurenic acid via interference with kynurenine aminotransferases in rats. Neurosci Lett 330:49-52 
Marchi M, Risso F, Viola C, Cavazzani P, Raiteri M (2002) Direct evidence that releasestimulating alpha $7 *$ nicotinic cholinergic receptors are localized on human and rat brain glutamatergic axon terminals. J Neurochem 80:1071-1078

McGeer EG, McGeer PL (1976) Duplication of biochemical changes of Huntington's chorea by intrastriatal injections of glutamic and kainic acids. Nature 263:517-519

Merino M, Vizuete ML, Cano J, Machado A (1999) The non-NMDA glutamate receptor antagonists 6-cyano-7-nitroquinoxaline-2,3-dione and 2,3-dihydroxy-6-nitro-7-

sulfamoylbenzo(f)quinoxaline, but not NMDA antagonists, block the intrastriatal neurotoxic effect of MPP+. J Neurochem 73:750-757

Miranda AF, Boegman RJ, Beninger RJ, Jhamandas K (1997) Protection against quinolinic acidmediated excitotoxicity in nigrostriatal dopaminergic neurons by endogenous kynurenic acid. Neuroscience 78:967-975

Misgeld U (2004) Innervation of the substantia nigra. Cell Tissue Res 318:107-114 Ogawa T, Matson WR, Beal MF, Myers RH, Bird ED, Milbury P, Saso S (1992) Kynurenine pathway abnormalities in Parkinson's disease. Neurology 42:1702-1706

Moroni F, Russi P, Gallo-Mezo MA, Moneti G, Pellicciari R (1991) Modulation of quinolinic and kynurenic acid content in the rat brain: effects of endotoxin and nicotinylalanine. $\mathrm{J}$ Neurochem 57:1630-1635

Okuda S, Nishiyama N, Saito H, Katsuki H (1998) 3-Hydroxykynurenine, an endogenous oxidative stress generator, causes neuronal cell death with apoptotic features and region selectivity. J Neurochem 70:299-307

Okuno E, Nakamura M, Schwarcz R (1991) Two kynurenine aminotransferases in human brain. Brain Res 542:307-312

Olney JW (1969) Brain lesions, obesity, and other disturbances in mice treated with monosodium glutamate. Science 164:719-721

Parli CJ, Krieter P, Schmidt B (1980) Metabolism of 6-chlorotryptophan to 4-chloro-3hydroxyanthranilic acid: A potent inhibitor of 3-hydroxyanthranilic acid oxidase. Arch Biochem Biophys 203:161-166

Pearson SJ, Reynolds GP (1992) Increased brain concentrations of a neurotoxin, 3hydroxykynurenine, in Huntington's disease. Neurosci Lett 144:199-201

Perkins MN, Stone TW (1982) An iontophoretic investigation of the actions of convulsant kynurenines and their interaction with the endogenous excitant quinolinic acid. Brain Res

247:184-187

Prescott C, Weeks AM, Staley KJ, Partin KM (2006) Kynurenic acid has a dual action on AMPA receptor responses. Neurosci Lett 402:108-112

Reichmann H, Riederer P (1989) Biochemical analyses of respiratory chain enzymes in different brain regions of patients with Parkinson's disease. BMFT Symposium “Morbus Parkinson und andere Basalganglienerkrankungen", Bad Kissingen, p44 (abstract)

Rios C, Santamaria A (1991) Quinolinic acid is a potent lipid peroxidant in rat brain homogenates. Neurochem Res 16:1139-1143 
Robotka H, Toldi J, Vécsei L (2008) L-kynurenine: metabolism and mechanism of neuroprotection. Future Neurol 3:169-188

Rózsa É, Robotka H, Vécsei L, Toldi J (2008) The Janus-face kynurenic acid. J Neural Transm 115:1087-1091

Sapko MT, Guidetti P, Yu P, Tagle DA, Pellicciari R, Schwarcz R (2006) Endogenous kynurenate controls the vulnerability of striatal neurons to quinolinate: Implications for Huntington's disease.

Exp Neurol 197:31-40

Sas K, Robotka H, Toldi J, Vécsei L (2007) Mitochondria, metabolic disturbances, oxidative stress and the kynurenine system, with focus on neurodegenerative disorders. J Neurol Sci 257:221-239 Schapira AH, Cooper JM, Dexter D, Jenner P, Clark JB, Marsden CD (1989) Mitochondrial complex I deficiency in Parkinson's disease. Lancet 1:1269

Schwarcz R (2004) The kynurenine pathway of tryptophan degradation as a drug target. Curr Opin Pharmacol 4:12-17

Schwarcz R, Köhler C (1983) Differential vulnerability of central neurons of the rat to quinolinic acid. Neurosci Lett 38:85-90

Schwarcz R, Okuno E, White RJ, Bird ED, Whetsell WO Jr (1988) 3-Hydroxyanthranilate oxygenase activity is increased in the brains of Huntington disease victims. Proc Natl Acad Sci USA 85:4079-4081

Smith Y, Raju DV, Pare JF, Sidibe M (2004) The thalamostriatal system: a highly specific network of the basal ganglia circuitry. Trends Neurosci 27:520-527

Stahl WL, Swanson PD (1974) Biochemical abnormalities in Huntington's chorea brains. Neurology 24:813-819

Stone TW (2000) Development and therapeutic potential of kynurenic acid and kynurenine derivatives for neuroprotection. Trends Pharmacol Sci 21:149-154

Stone TW, Perkins MN (1981) Quinolinic acid: a potent endogenous excitant at amino acid receptors in CNS. Eur J Pharmacol 72:411-412

Tavares RG, Tasca CI, Santos CE, Alves LB, Porciúncula LO, Emanuelli T, Souza DO (2002) Quinolinic acid stimulates synaptosomal glutamate release and inhibits glutamate uptake into astrocytes. Neurochem Int 40:621-627

Ułas J, Weihmuller FB, Brunner LC, Marshall JF, Cotman CW (1994) Selective increase of NMDA-sensitive glutamate binding in the striatum of Parkinson's disease, Alzheimer's disease, and mixed Parkinson's disease/Alzheimer's disease patients: an autoradiographic study. J

Neurosci 14:6317-6324

Vécsei L (ed) (2005) Kynurenines in the brain. From experiments to clinics. Nova, New York Vécsei L, Beal MF (1991) Comparative behavioural and neurochemical studies with striatal kainic acid- or quinolinic acid-lesioned rats. Pharmacol Biochem Behav 39:473-478

Wolf H (1974) Studies on tryptophan metabolism in man: The effect of hormones and vitamin B6 on urinary excretion of metabolites of the kynurenine pathway. Scand J Clin Lab Invest 136(Suppl.):1-186

Wu HQ, Lee SC, Schwarcz R (2000) Systemic administration of 4-chlorokynurenine prevents quinolinate neurotoxicity in the rat hippocampus. Eur J Pharmacol 390:267-274 
Yu P, Li Z, Zhang L, Tagle DA, Cai T (2006) Characterizítion of kynurenine aminotransferase III, a novel member of a phylogenetically conserved KAT family. Gene 365:111-118

\section{Figure legends}

Figure 1 Common pathways in chronic neurodegenerative disorders.

Figure 2 The kynurenine pathway of the tryptophan metabolism. 